\title{
Impacto da pandemia de COVID-19 nas emissões veiculares no Brasil no período de janeiro a maio de 2020
}

\author{
Impact of the COVID-19 pandemic on vehicle \\ emissions in Brazil from January to May 2020
}

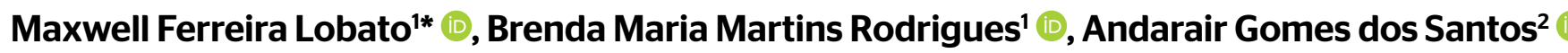

口-

\begin{abstract}
RESUMO
No presente trabalho foi realizada a estimativa das emissões dos gases de efeito estufa ( $\mathrm{CO}_{2}$ eq), monóxido de carbono (CO), óxido de nitrogênio (NOx), material particulado (MP), aldeído (RCHO) e hidrocarboneto não metano (NMHC) dos veículos licenciados nos cinco primeiro meses do ano de 2020 no Brasil. Os resultados foram comparados com as emissões veiculares da frota licenciada no mesmo período do ano de 2019 a fim de verificar o impacto da pandemia de COVID-19 nos referidos licenciamentos, nas emissões e, consequentemente, na qualidade do ar do país. Os resultados apontaram redução de 14\% nas emissões dos gases de efeito estufa, com diminuição observada para todos os veículos, exceto para os caminhões semipesados, que tiveram incremento nas emissões de gases de efeito estufa de 12,8\%. Os demais poluentes também reduziram, em 12,5\% para o CO, em 29,6\% para o NOx, em 24,1\% para o MP, em 21,5\% para o $\mathrm{RCHO}$ e em 16,3\% para o NMHC. Por fim, quanto ao total de poluentes acumulados, entre todos os veículos analisados, os únicos que tiveram aumento nas emissões em relação a 2019, de 2,1\%, foram as motocicletas com tecnologia flexfuel, que são abastecidas preferencialmente com etanol hidratado. Com isso, pôde-se concluir que a pandemia da COVID-19, por meio das medidas de restrição e isolamento social adotadas no país para frear a transmissão da doença, impactou positivamente a qualidade do ar no Brasil no período analisado.
\end{abstract}

Palavras-chave: Covid-19; emissões de poluentes; veículos automotores.

\begin{abstract}
The estimated emissions of greenhouse gases $\left(\mathrm{CO}_{2}\right.$ eq), carbon monoxide (CO), nitrogen oxide (NOx), particulate matter (PM), aldehyde (RCHO) and non-methane hydrocarbon (NMHC) from vehicles licensed in the first five months of 2020 in Brazil were calculated in the present study, and the results compared with vehicular emissions from the licensed fleet in the same period of the year 2019, in order to verify the impact of the COVID-19 pandemic on these permits, emissions and, consequently, air quality in the country. The results showed a 14\% reduction in greenhouse gas emissions, with a decrease observed for all vehicles, except for semi heavy trucks, which had a $12.8 \%$ increase in GHG emissions. The other pollutants also decreased, being 12.5\% for CO, 29.6\% for NOx, 24.1\% for PM, $21.5 \%$ for RCHO, and $16.3 \%$ for NMHC. Finally, in relation to the total accumulated pollutants, among all vehicles analyzed, the only ones that had a 2.1\% increase in emissions in relation to 2019 were the motorcycles with flexfuel technology, which are preferably fueled with hydrated ethanol. Thus, it was concluded that the COVID-19 pandemic, through the measures of restriction and social isolation adopted in the country to curb the transmission of the disease, had a positive impact on air quality in Brazil during the analyzed period.
\end{abstract}

Keywords: COVID-19; pollutant emissions; auto-vehicles.

\section{INTRODUÇÃO}

Desde os relatos de uma pneumonia de origem não conhecida vindos da China, passando pela identificação do novo coronavírus SARS-CoV-2 como agente causador da doença COVID-19, o mundo enfrenta grandes desafios para conter seu avanço e elucidar seu tratamento (FERREIRA NETTO; CORRÊA, 2020).
Porém, apesar de toda a consternação com a quantidade de vidas perdidas e do impacto socioeconômico que aflige o mundo, um ponto positivo tem sido observado durante a pandemia: a diminuição da poluição atmosférica em várias partes da terra por causa das medidas de isolamento social adotadas por praticamente todos os países.

'Coordenação da Engenharia Ambiental e Sanitária, Universidade Federal do Maranhão - São Luís (MA), Brasil.

2Departamento de Ciências Naturais, Matemática e Estatística, Universidade Federal Rural do Semi-Árido - Mossoró (RN), Brasil.

*Autor correspondente: maxwell.lobato@ufma.br

Conflitos de interesse: os autores declaram não haver conflito de interesses.

Financiamento: nenhum.

Recebido: 22/07/2O2O - Aceito: 15/09/2O2O - Reg. ABES: 20200261 
Esse fato positivo é registrado por diversos autores, entre eles Rosenbloom e Markard (2020), ao citarem que desde o estágio inicial da pandemia tem sido observado que os bloqueios mundiais diminuíram a poluição do ar e as emissões de gases de efeito estufa; e Dutheil, Baker e Navel (2020), que trouxeram no seu artigo a informação de que os satélites de monitoramento da National Aeronautic and Space Administration (NASA) identificaram, entre janeiro e fevereiro de 2020, na China central, diminuição de $30 \%$ na concentração de dióxido de nitrogênio $\left(\mathrm{NO}_{2}\right)$ e de $20 \%$ na de dióxido de carbono.

Além desses autores, Niemann (2017 apud Sciomer et al., 2020) afirmou que a poluição do ar é responsável por entre 3 e 7 milhões de mortes em todo o mundo por ano. Além disso, têm surgido estudos que sugerem que o material particulado (MP) possa contribuir, também, com a disseminação do SARS-CoV-2, conforme evidências empíricas apresentadas por Sharma e Balyan (2020).

Ainda no contexto da poluição atmosférica, Sciomer et al. (2020) estudaram a poluição urbana e demonstraram que ela é um complexo coquetel de produtos químicos, amplamente caracterizado por gases, líquidos semivoláteis e partículas, cujas fontes de emissão, segundo Farias (2013 apud Oscar JR.; Rocha, 2020), são basicamente os veículos automotores (fontes móveis) e as indústrias (fontes fixas), sendo as primeiras as mais importantes.

Ciente dessa informação, o Brasil, com a finalidade de estabelecer estratégias para o controle, preservação e recuperação da qualidade do ar, instituiu, no ano de 1989, o Programa Nacional de Controle da Qualidade do Ar (PRONAR), com base na Resolução do Conselho Nacional do Meio Ambiente (CONAMA) n 5 (BRASIL, 1989), que pressupõe, entre outros, a implantação do Programa Nacional de Inventários de Fontes Poluidoras do Ar, com o objetivo de definir os primeiros limites de emissão para a frota de veículos que circula no território nacional. O $1^{\circ}$ Inventário foi produzido no ano de 2011 (BRASIL, 2011) e sua metodologia serviu de inspiração para este trabalho.

Em relação à COVID-19, no Brasil, segundo dados do Ministério da Saúde (BRASIL, 2020b), 514.200 pessoas foram acometidas pela doença até o mês de maio de 2020, fazendo com que o país se tornasse o segundo do mundo com o maior número de infectados (OMS, 2020). No dia 26 de fevereiro foi confirmado o primeiro caso no país (BRASIL, 2020b), e nessa data o índice médio de isolamento social da população brasileira foi de $34,7 \%$ (INLOCO, 2020). Com a notificação de novos casos e as políticas de conscientização, os números foram aumentando e atingiram seu ápice no dia 22 de março, com índice de isolamento de 62,2\% (INLOCO, 2020). Esse índice foi decaindo e, no dia 31 de maio, estava em 49,8\% (INLOCO, 2020), ainda assim 15\% maior do que no início da pandemia. No entanto, apesar de aproximadamente metade da população brasileira ter ficado em isolamento social entre os meses de fevereiro e maio, existem poucas informações sobre a influência desse período de menor movimentação de pessoas e veículos na qualidade do ar no país.

Com base nessas informações, o presente trabalho teve como objetivo estimar as emissões de poluentes dos veículos dos ciclos Otto e Diesel, que foram licenciados nos cinco primeiro meses do ano de 2020 no Brasil, e comparar os resultados com as emissões veiculares daqueles licenciados no mesmo período do ano de 2019 a fim de verificar o impacto da pandemia e do isolamento social na venda desses veículos, nas suas emissões e, consequentemente, na qualidade do ar do país. Para isso foram estimadas as emissões de monóxido de carbono
(CO), óxido de nitrogênio (NOx), hidrocarboneto não metano (NMHC), aldeído (RCHO) e MP, além dos gases de efeito estufa, para a gasolina e o diesel, utilizados neste trabalho em termos de dióxido de carbono equivalente $\left(\mathrm{CO}_{2} \mathrm{eq}\right)$.

\section{METODOLOGIA}

Para os cálculos de emissão dos gases de efeito estufa $\left(\mathrm{CO}_{2}, \mathrm{CH}_{4}\right.$ e $\left.\mathrm{N}_{2} \mathrm{O}\right)$ foi utilizada a metodologia top-down (SENAI, 2017), que consiste, primeiramente, em converter a unidade de volume do combustível em unidade de energia. Esse cálculo foi realizado utilizando-se a Equação 1.

$\mathrm{CE}=\mathrm{CA}$. Fconv $.45,2 \times 10^{-3}$. Fcorr

Em que:

$\mathrm{CE}=$ consumo de energia $(\mathrm{TJ})$;

$\mathrm{CA}=\mathrm{o}$ consumo aparente do combustível $\left(\mathrm{m}^{3}\right)$ por $45,2 \times 10^{-3}$, para transformar a quantidade de energia de $1 \mathrm{tEP}$ brasileiro para terajoule (TJ) (CRUVINEL; PINTO; GRANEMANN, 2012). Os valores foram retirados das estatísticas da Agência Nacional de Petróleo, Gás Natural e Biocombustíveis (ANP, 2020a); Fconv $=o$ fator de conversão, cujos valores foram retirados do EPE (2020); Fcorr $=\mathrm{o}$ fator de correção de poder calorífico superior (PCS) para poder calorífico inferior (PCI). Para combustíveis sólidos e líquidos, o Fcorr $=0,95$ e, para combustíveis gasosos, o Fcorr = 0,90 (ÁLVARES JR.; LINKE, 2001).

Com o consumo energético calculado, além dos respectivos fatores de emissão que neste trabalho foram retirados do Painel Intergovernamental sobre Mudança do Clima (IPCC, 2006), estimou-se individualmente a emissão de cada gás pela Equação 2 .

\section{$\mathrm{EGEE}=\mathrm{CE}$. Femiss}

Em que:

EGEE = a emissão do gás de efeito estufa $(\mathrm{kg})$;

$\mathrm{CE}=\mathrm{o}$ consumo de energia $(\mathrm{TJ})$;

Femiss $=\mathrm{o}$ fator de emissão $\left(\mathrm{kg} \cdot \mathrm{T}^{-1}\right)$.

Por fim, como o $\mathrm{CO}_{2}$ é o principal GEE, os outros gases precisam ser equiparados a ele para se chegar a uma unidade comum, o dióxido de carbono equivalente $\left(\mathrm{CO}_{2}\right.$ eq) (USEPA, 2020).

Para isso foi usada a Equação 3.

$\mathrm{ECO}_{2}$ eq $=\mathrm{ECO}_{2}+\left(\mathrm{ECH}_{4} \cdot 25\right)+\left(\mathrm{EN}_{2} \mathrm{O} .298\right)$

Em que:

$\mathrm{ECO}_{2}$ eq = a emissão de dióxido de carbono equivalente (tonelada);

$\mathrm{ECO}_{2}=$ a emissão de dióxido de carbono (tonelada);

$\mathrm{ECH}_{4}=$ a emissão de metano (tonelada);

$\mathrm{EN}_{2} \mathrm{O}=$ a emissão de óxido nitroso (tonelada).

Já para os cálculos dos demais poluentes não GEE, a estimativa de emissão foi realizada utilizando-se a metodologia bottom-up (BRASIL, 2014; SINGH; SHARMA; AGRAWAL, 2017; CETESB, 2019), por meio da Equação 4. 


\section{$\mathrm{EP}=\mathrm{FV}, \mathrm{IU} . \mathrm{Fe}$}

Em que:

$\mathrm{EP}=\mathrm{a}$ taxa de emissão do poluente $\left(\mathrm{g} \cdot \mathrm{ano}^{-1}\right)$;

$\mathrm{FV}=\mathrm{a}$ frota de veículos novos;

$\mathrm{IU}=\mathrm{a}$ intensidade de uso dos veículos $\left(\mathrm{km} \cdot \mathrm{ano}^{-1}\right)$;

$\mathrm{Fe}=\mathrm{o}$ fator de emissão do poluente $\left(\mathrm{g} \cdot \mathrm{km}^{-1}\right)$.

Os fatores de emissão foram retirados do Relatório da CETESB (2019) por falta de informações mais recentes; e a quantidade de veículos licenciados retirada das estatísticas da ANFAVEA (2020) e da ABRACICLO (2020), sendo desagregados por tipo de combustível (gasolina, etanol, flexfuel e diesel), por tipo de uso e capacidade (BRASIL, 2014). Em relação aos veículos e motocicletas flexfuel, a frota foi dividida entre aquela cujos usuários optaram por utilizar gasolina como combustível preferencial, e aquela cuja preferência foi por etanol hidratado, sendo essas informações retiradas da curva apresentada nos anexos do inventário nacional (BRASIL, 2011). Ademais, com a finalidade de corrigir a quantidade de veículos efetivamente em circulação nos períodos propostos, foram utilizadas as curvas de sucateamento informadas no Relatório da Companhia Ambiental do Estado de São Paulo (CETESB, 2019), que são equações estatisticamente ajustadas ao perfil da frota veicular brasileira (LOPES et al., 2018).

Já em relação aos procedimentos para cálculo da intensidade de uso, por causa das suas incertezas e da falta de informações atualizadas, adotaram-se neste trabalho os valores de referência fornecidos por CETESB (2019). Além disso, conforme proposto por Brasil (2011) e replicado em outros trabalhos (LOPES et al., 2018; CETESB, 2019), foi necessário comparar o consumo estimado de combustível da frota analisada com o consumo de combustível observado (quantidade de combustível consumido no país) no mesmo período, por meio de informações retiradas das estatísticas da ANP (2020a).

O consumo estimado de combustível foi calculado pela Equação 5.

Cest $=\mathrm{FV} \cdot \mathrm{IUref} \cdot \mathrm{R}^{-1}$

Em que:

Cest $=$ o consumo estimado de combustível para um determinado veículo; $\mathrm{FV}=\mathrm{a}$ frota de veículos novos;

$\mathrm{R}=\mathrm{a}$ autonomia do veículo $\left(\mathrm{km} \mathrm{L}^{-1}\right)$. Neste trabalho, os valores de autonomia foram retirados do Relatório da CETESB (2019).

A razão entre o consumo estimado e o consumo observado gerou um fator de correção para o ajuste dos valores de intensidade de uso, que foram calculadas pela Equação 6.

IUajust $=$ IUref $\cdot\left(\right.$ Cobs $\cdot$ Cest $\left.^{-1}\right)$

Em que:

IUref $=$ intensidade de uso de referência $\left(\mathrm{km}^{\mathrm{ano}} \mathrm{o}^{-1}\right)$;

Cobs = consumo de combustível observado $\left(\mathrm{L} \cdot \mathrm{ano}^{-1}\right)$;

Cest $=$ consumo de combustível estimado $\left(\right.$ L.ano $\left.^{-1}\right)$.
RESULTADOS E DISCUSSÃO

Quantidade de veículos licenciados e estimativa das emissões de gases de efeito estufa de janeiro a maio de 2019 e 2020

A frota de veículos licenciada em 2019 e a estimativa das emissões de escapamento dos gases do efeito estufa, desagregados por categoria de veículo e combustível, são apresentadas na Tabela 1.

Segundo a Tabela 1, no período analisado foram licenciados no país 1.519.924 veículos e emitidas 99.620 .725 toneladas de gases de efeito estufa, $37 \%$ delas advindas dos veículos do ciclo Otto e $63 \%$ dos veículos do ciclo Diesel, resultado coerente com Brasil (2014).

Já para o ano de 2020, a quantidade de veículos licenciados e a estimativa das emissões de escapamento dos gases do efeito estufa são apresentadas na Tabela 2.

Os dados apresentados na tabela mostram que, em 2020, foram licenciados 964.522 veículos no Brasil, 37\% a menos do que nos mesmos meses de 2019. Os ônibus foram os que mais sofreram queda, de $43 \%$, seguidos pelos caminhões, com $26 \%$, automóveis e comerciais leves, com $39 \%$, e pelas motocicletas, com $32 \%$.

Quanto às emissões de GEE, os resultados referentes aos cinco primeiros meses de 2020 em relação ao mesmo período de 2019, desagregados por tipo de veículo e combustível, são apresentados na Figura 1.

Em 2020, o total de GEE emitido foi de 85.275.922 toneladas, redução de $14 \%$ em relação a 2019, sendo $71 \%$ provenientes da queima de óleo diesel e $29 \%$ da queima de gasolina. Todos os veículos tiveram diminuição nas emissões

Tabela 1 - Frota de veículos e estimativa das emissões de gases de efeito estufa de origem veicular por tipo de combustível e veículo entre janeiro e maio de 2019

\begin{tabular}{|c|c|c|c|c|}
\hline \multicolumn{3}{|l|}{ Veículos } & Frota & $\mathrm{CO}_{2}$ eq $(t)$ \\
\hline \multirow{3}{*}{ Automóveis } & \multicolumn{2}{|c|}{ Gasolina C } & 28.200 & 979.561 \\
\hline & \multicolumn{2}{|c|}{ Flex. Gasolina C } & 621.321 & 21.582.154 \\
\hline & \multicolumn{2}{|c|}{ Flex. Etanol } & 231.523 & NA \\
\hline \multirow{3}{*}{$\begin{array}{l}\text { Comerciais } \\
\text { Leves }\end{array}$} & \multicolumn{2}{|c|}{ Gasolina C } & 4.853 & 168.570 \\
\hline & \multicolumn{2}{|c|}{ Flex. Gasolina C } & 38.715 & 1.344 .807 \\
\hline & \multicolumn{2}{|c|}{ Flex. Etanol } & 14.507 & NA \\
\hline $\begin{array}{l}\text { Comerciais } \\
\text { Leves }\end{array}$ & \multicolumn{2}{|c|}{ Diesel } & 94.368 & 41.654 .422 \\
\hline \multirow{5}{*}{ Caminhões } & \multicolumn{2}{|c|}{ Semileves } & 2.296 & 1.013 .464 \\
\hline & \multicolumn{2}{|c|}{ Caminhões Leves } & 4.629 & 2.043 .260 \\
\hline & \multicolumn{2}{|c|}{ Médios } & 3.874 & 1.709 .999 \\
\hline & \multicolumn{2}{|c|}{ Semipesados } & 8.332 & 3.677 .779 \\
\hline & \multicolumn{2}{|c|}{ Pesados } & 19.963 & 8.811 .750 \\
\hline \multirow{2}{*}{ Ônibus } & \multicolumn{2}{|c|}{ Ônibus urbano } & 6.800 & 3.001 .753 \\
\hline & \multicolumn{2}{|c|}{ Ônibus rodoviário } & 1.303 & 575.386 \\
\hline \multirow{6}{*}{ Motocicleta } & \multirow{2}{*}{ Gasolina C } & $<150$ cc & 171.553 & 5.959 .049 \\
\hline & & $>150 \mathrm{cc}$ & 34.889 & 1.211 .889 \\
\hline & \multirow{2}{*}{$\begin{array}{c}\text { Flex. Gasolina } \\
\text { C }\end{array}$} & $<150$ cc & 140.834 & 4.891 .999 \\
\hline & & $>150 \mathrm{cc}$ & 28.641 & 994.883 \\
\hline & \multirow{2}{*}{ Flex. Etanol } & $<150$ cc & 52.619 & NA \\
\hline & & $>150 \mathrm{cc}$ & 10.701 & NA \\
\hline
\end{tabular}

$\mathrm{CO}_{2}$ eq: emissões dos gases de efeito estufa; Flex:: flexfuel; $\mathrm{NA}$ : não se aplica. Fonte: elaborada pelos autores. 
Tabela 2 - Frota de veículos e estimativa das emissões de gases de efeito estufa de origem veicular por tipo de combustível e veículo entre janeiro e maio de 2020.

\begin{tabular}{|c|c|c|c|c|}
\hline \multicolumn{3}{|l|}{ Veículo } & Frota & $\mathrm{CO}_{2}$ eq $(\mathrm{t})$ \\
\hline \multirow{3}{*}{$\begin{array}{l}\text { Automóveis } \\
\text { Otto }\end{array}$} & \multicolumn{2}{|c|}{ Gasolina C } & 16.488 & 741.876 \\
\hline & \multicolumn{2}{|c|}{ Flex. Gasolina C } & 418.341 & 18.822 .812 \\
\hline & \multicolumn{2}{|c|}{ Flex. Etanol } & 92.714 & NA \\
\hline \multirow{3}{*}{$\begin{array}{l}\text { Comerciais } \\
\text { Leves }\end{array}$} & \multicolumn{2}{|c|}{ Gasolina C } & 3.382 & 152.176 \\
\hline & \multicolumn{2}{|c|}{ Flex. Gasolina C } & 25.727 & 1.157 .539 \\
\hline & \multicolumn{2}{|c|}{ Flex Etanol } & 6.233 & NA \\
\hline $\begin{array}{l}\text { Comerciais } \\
\text { Leves }\end{array}$ & \multicolumn{2}{|c|}{ Diesel } & 71.083 & 41.053 .818 \\
\hline \multirow{5}{*}{ Caminhões } & \multicolumn{2}{|c|}{ Semileves } & 1.511 & 872.672 \\
\hline & \multicolumn{2}{|c|}{ Leves } & 3.058 & 1.766 .135 \\
\hline & \multicolumn{2}{|c|}{ Médios } & 2.631 & 1.519 .523 \\
\hline & \multicolumn{2}{|c|}{ Semipesados } & 7.302 & 4.217 .240 \\
\hline & \multicolumn{2}{|c|}{ Pesados } & 14.404 & 8.318 .970 \\
\hline \multirow{2}{*}{ Ônibus } & \multicolumn{2}{|c|}{ Ônibus urbano } & 3.835 & 2.214 .884 \\
\hline & \multicolumn{2}{|c|}{ Ônibus rodoviário } & 812 & 468.971 \\
\hline \multirow{6}{*}{ Motocicleta } & \multirow{2}{*}{ Gasolina C } & $<150$ cc & 116.000 & 5.219 .295 \\
\hline & & $>150 \mathrm{cc}$ & 23.591 & 1.061 .445 \\
\hline & \multirow{2}{*}{$\begin{array}{l}\text { Flex. Gasolina } \\
\text { C }\end{array}$} & $<150$ cc & 104.908 & 4.720 .242 \\
\hline & & $>150 \mathrm{cc}$ & 21.335 & 959.953 \\
\hline & \multirow{2}{*}{ Flex. Etanol } & $<150$ cc & 25.900 & NA \\
\hline & & $>150$ cc & 5.267 & NA \\
\hline
\end{tabular}

$\mathrm{CO}_{2}$ eq: emissões dos gases de efeito estufa; Flex:: flexfuel; NA: não se aplica. Fonte: elaborada pelos autores

de GEE, exceto os caminhões semipesados, que emitiram 12,8\% a mais em relação a 2019, resultado que pode ser indício do aumento na sua intensidade de uso pelo incremento nos transportes de encomendas domésticas no país (E-COMMERCE.BRASIL, 2020). Esse tipo de caminhão é o mais utilizado para o transporte de eletroeletrônicos, eletrodomésticos da linha branca, remédios, produtos têxteis e outras cargas com baixo e médio peso específico, mas com grande volume em baús (WLM/SCANIA, 2019).

\section{Comparação da estimativa das emissões dos demais poluentes entre 2019 e 2020}

A estimativa das emissões dos demais poluentes nos cinco primeiros meses de 2019 é apresentada na Tabela 3.

Em relação às estimativas de emissão de $\mathrm{CO}$, os resultados apontam que $46 \%$ foram decorrentes dos automóveis, $40 \%$ das motocicletas, $6 \%$ dos caminhões, $4 \%$ dos comerciais leves (2,3\% do ciclo Otto e $1,7 \%$ do Diesel) e $3 \%$ dos ônibus. Dos automóveis e motocicletas, que juntos somaram $86 \%$ das emissões de CO - resultado concordante com Brasil (2014) e CETESB (2019) - , as subcategorias que emitiram a maior quantidade foram os com tecnologia flexfuel.

Quanto às emissões de $\mathrm{NOx}$, os caminhões foram os que contribuíram com a maior parcela, de $60 \%$, seguidos pelos ônibus, com $20 \%$, o que indica que esse poluente é característico da queima do óleo diesel, conforme apresentado por Brasil (2014) e CETESB (2019).
Em relação ao MP, observa-se que os veículos movidos a diesel também foram os que contribuíram com a maior parcela desse poluente, sendo $36 \%$ referentes aos comerciais leves a diesel, $28 \%$ aos caminhões e $11 \%$ aos ônibus. Já para os veículos do ciclo Otto, as motocicletas foram as responsáveis pela maior emissão, com 16\%.

No tocante às emissões de RCHO, que foram medidas apenas para os automóveis e comerciais leves do ciclo Otto por não existirem dados disponíveis para os demais veículos (CETESB, 2019), aqueles com tecnologia flexfuel que usam o etanol como combustível preferencial foram responsáveis por 73\% das emissões desse poluente, corroborando os achados de Brasil (2014) e CETESB (2019).

Enfim, para o NMHC, 77\% das emissões foram decorrentes dos veículos do ciclo Otto e, desses, $65 \%$ de veículos cujos usuários utilizam gasolina como combustível preferencial, informação confirmada por Brasil (2014).

Para o ano de 2020, a estimativa das emissões de escapamento dos demais poluentes nos cinco primeiros meses é apresentada na Tabela 4.

Em relação ao CO, houve diminuição das emissões para todos os veículos analisados, exceto para as motocicletas flexfuel, que utilizaram o etanol como combustível preferencial, as quais tiveram aumento de 2,1\% em relação a 2019. Isso indica que pode ter havido acréscimo na intensidade de uso desses veículos, provavelmente pelo incremento nas entregas de alimentos e demais encomendas em domicílio (E-COMMERCE.BRASIL, 2020). Além do mais, o aumento das emissões aponta para a preferência pelo uso do álcool hidratado em detrimento da gasolina, que pode ser explicada pela razão de preço etanol/gasolina abaixo de 0,7 nos meses de abril e maio de 2020 (ANP, 2020b).

Quanto ao NOx, destaca-se a redução de $27 \%$ para os caminhões, mostrando uma diminuição nas emissões que vai além da queda nas vendas desse tipo de veículo e que pode ser um indicativo do decréscimo da demanda geral de carga no Brasil, corroborando os achados de NTC\&Logística (2020). Já para os ônibus, a redução foi de $43 \%$, o que demonstra menor circulação desses veículos e valida a informação de que houve diminuição nas viagens nacionais e suspensão das internacionais no período analisado (BRASIL, 2020a).

Sobre o MP, observa-se decréscimo de $31 \%$ nas emissões dos veículos com motor a diesel, concordante com a queda nas vendas e a diminuição de uso.

Para as emissões de RCHO, houve redução de 15,3\%, que ficou abaixo da porcentagem de queda dos veículos Otto. Porém, como a diminuição nos licenciamentos dos comerciais leves foi cerca de $1 \%$ menor do que dos automóveis, esse valor de emissão pode ser explicado pelo aumento da intensidade de uso daqueles veículos, usados para fins comerciais. Esse fato também pode explicar a redução de $9,6 \%$ de NMHC.

Em relação ao total de poluentes acumulados (soma de todos os gases e do MP), os resultados mostram que, em 2019, houve a emissão de 291.871 toneladas. Já para 2020, a emissão acumulada foi de 235.155 toneladas, uma redução de $19,4 \%$.

Por fim, a emissão dos poluentes acumulados, exceto os GEE, foi analisada para cada categoria de veículo e combustível e é apresentada na Figura 2.

Na Figura 2, observa-se que a categoria de veículo com maior redução nas emissões dos poluentes acumulados foi a dos ônibus, com $44,9 \%$, seguida da dos caminhões, com 27,3\% - mais um indício da diminuição da intensidade de uso, conforme já mencionado. Em relação aos automóveis, a redução foi de $13,7 \%$, e, para os comerciais leves, de $24,4 \%$. 


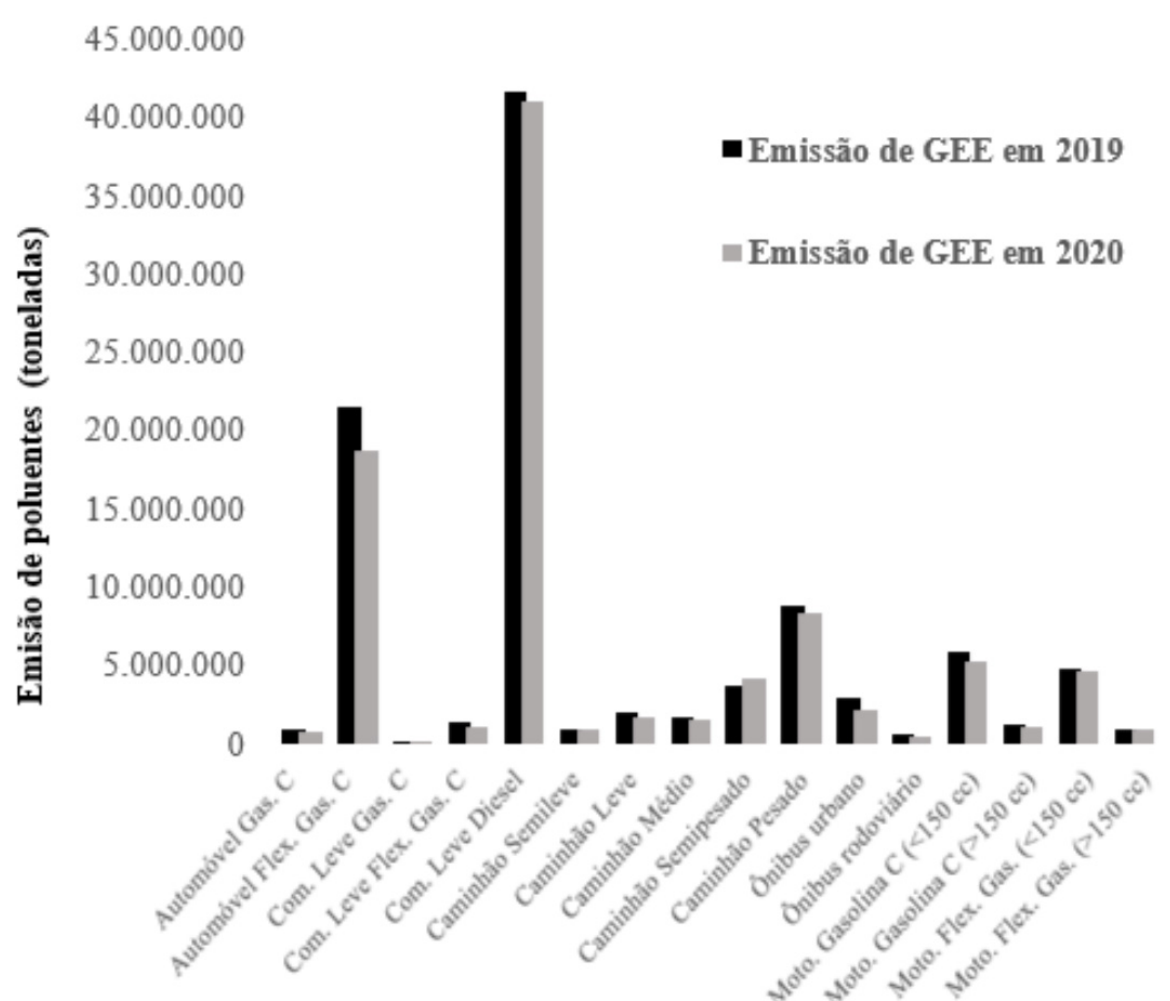

GEE: gases de efeito estufa; Com:: comerciais; Gas.: gasolina; Moto: motocicletas. Fonte: elaborada pelos autores.

Figura 1 - Estimativa da emissão de gases de efeito estufa nos cinco primeiros meses de 2020 em relação ao mesmo período de 2019, desagregados por tipo de veículo e combustivel.

Tabela 3 - Estimativa da emissão dos demais poluentes de origem veicular por tipo de combustível e veículo entre janeiro e maio de 2019.

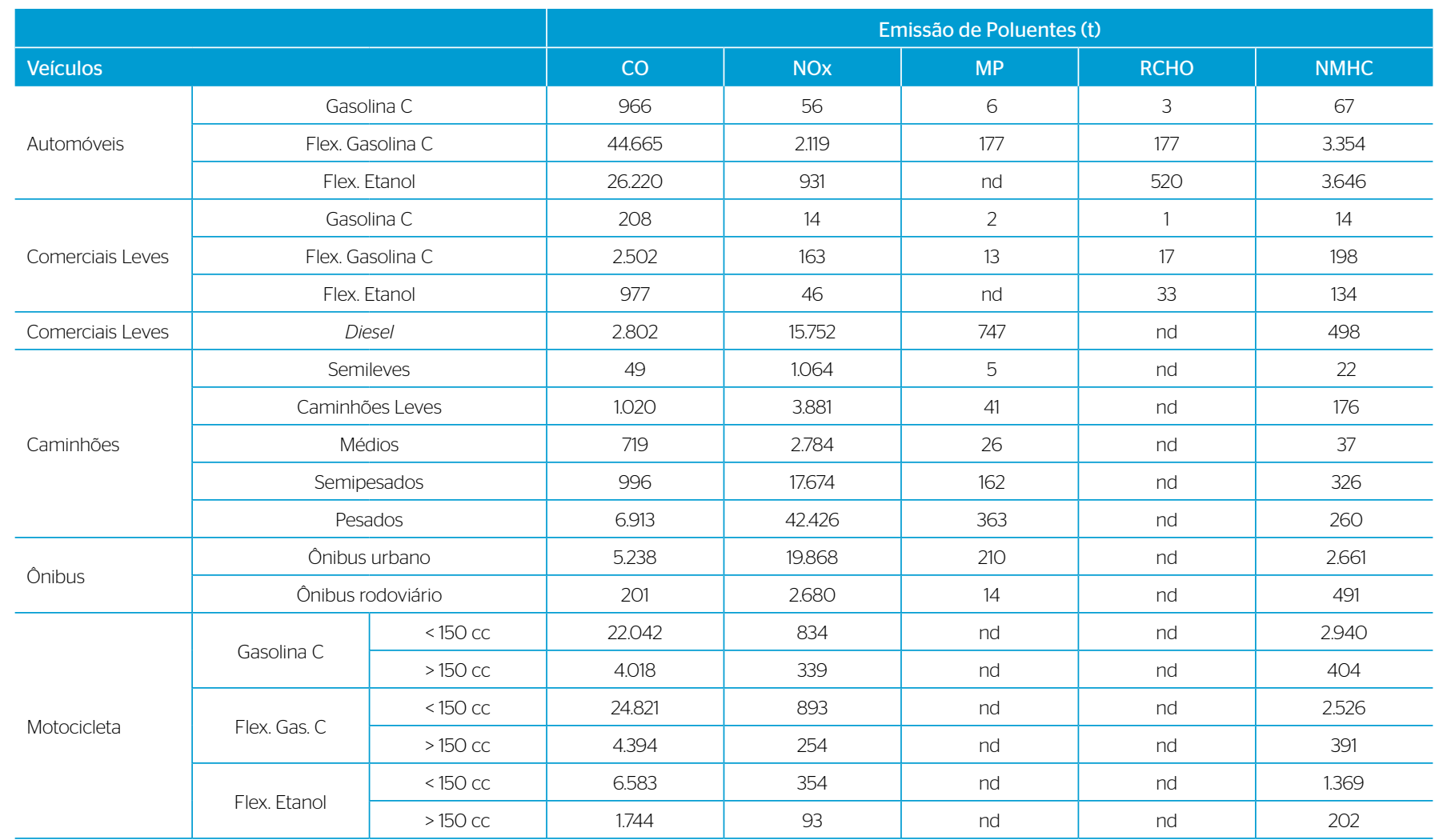

CO: monóxido de carbono; NOx: óxido de nitrogênio; MP: material particulado; RCHO: aldeído; NMHC: hidrocarboneto não metano; Flex: flexfuel; Gas:: gasolina; nd: não disponível. Fonte: elaborada pelos autores. 
Tabela 4 - Estimativa da emissão dos demais poluentes de origem veicular por tipo de combustível e veículo entre janeiro e maio de 2020.

\begin{tabular}{|c|c|c|c|c|c|c|c|}
\hline & & & \multicolumn{5}{|c|}{ Emissão de poluentes (t) } \\
\hline \multicolumn{3}{|l|}{ Veículos } & $\mathrm{CO}$ & NOx & MP & $\mathrm{RCHO}$ & NMHC \\
\hline \multirow{3}{*}{ Automóveis } & \multicolumn{2}{|c|}{ Gasolina C } & 742 & 43 & 4 & 2 & 51 \\
\hline & \multicolumn{2}{|c|}{ Flex. Gasolina C } & 39.532 & 1.875 & 156 & 156 & 2.969 \\
\hline & \multicolumn{2}{|c|}{ Flex. Etanol } & 21.779 & 773 & nd & 432 & 3.028 \\
\hline \multirow{3}{*}{ Comerciais Leves } & \multicolumn{2}{|c|}{ Gasolina C } & 191 & 13 & 1 & 1 & 13 \\
\hline & \multicolumn{2}{|c|}{ Flex. Gasolina C } & 2.186 & 142 & 11 & 15 & 173 \\
\hline & \multicolumn{2}{|c|}{ Flex. Etanol } & 871 & 41 & nd & 30 & 119 \\
\hline Comerciais Leves & \multicolumn{2}{|c|}{ Diesel } & 2.041 & 11.475 & 544 & nd & 363 \\
\hline \multirow{5}{*}{ Caminhões } & \multicolumn{2}{|c|}{ Semileves } & 31 & 677 & 3 & nd & 14 \\
\hline & \multicolumn{2}{|c|}{ Caminhões Leves } & 652 & 2.479 & 26 & nd & 113 \\
\hline & \multicolumn{2}{|c|}{ Médios } & 472 & 1.829 & 17 & nd & 24 \\
\hline & \multicolumn{2}{|c|}{ Semipesados } & 844 & 14.980 & 137 & nd & 276 \\
\hline & \multicolumn{2}{|c|}{ Pesados } & 4.824 & 29.605 & 253 & nd & 182 \\
\hline \multirow{2}{*}{ Ônibus } & \multicolumn{2}{|c|}{ Ônibus urbano } & 2.857 & 10.835 & 115 & nd & 1.451 \\
\hline & \multicolumn{2}{|c|}{ Ônibus rodoviário } & 121 & 1.615 & 9 & nd & 296 \\
\hline \multirow{6}{*}{ Motocicleta } & \multirow{2}{*}{ Gasolina C } & $<150$ cc & 19.592 & 741 & nd & nd & 2.614 \\
\hline & & $>150 \mathrm{cc}$ & 3.572 & 301 & nd & nd & 359 \\
\hline & \multirow{2}{*}{ Flex. Gasolina C } & $<150$ cc & 24.305 & 874 & nd & nd & 2.473 \\
\hline & & $>150 \mathrm{cc}$ & 4.303 & 249 & nd & nd & 383 \\
\hline & \multirow{2}{*}{ Flex. Etanol } & $<150$ cc & 6.721 & 361 & nd & nd & 1.398 \\
\hline & & $>150 \mathrm{cc}$ & 1.781 & 95 & nd & nd & 207 \\
\hline
\end{tabular}

CO: monóxido de carbono; NOx: Óxido de nitrogênio; MP: material particulado; RCHO: aldeído; NMHC: hidrocarboneto não metano; Flex: flexfuel; nd: não disponível. Fonte: elaborada pelos autores.

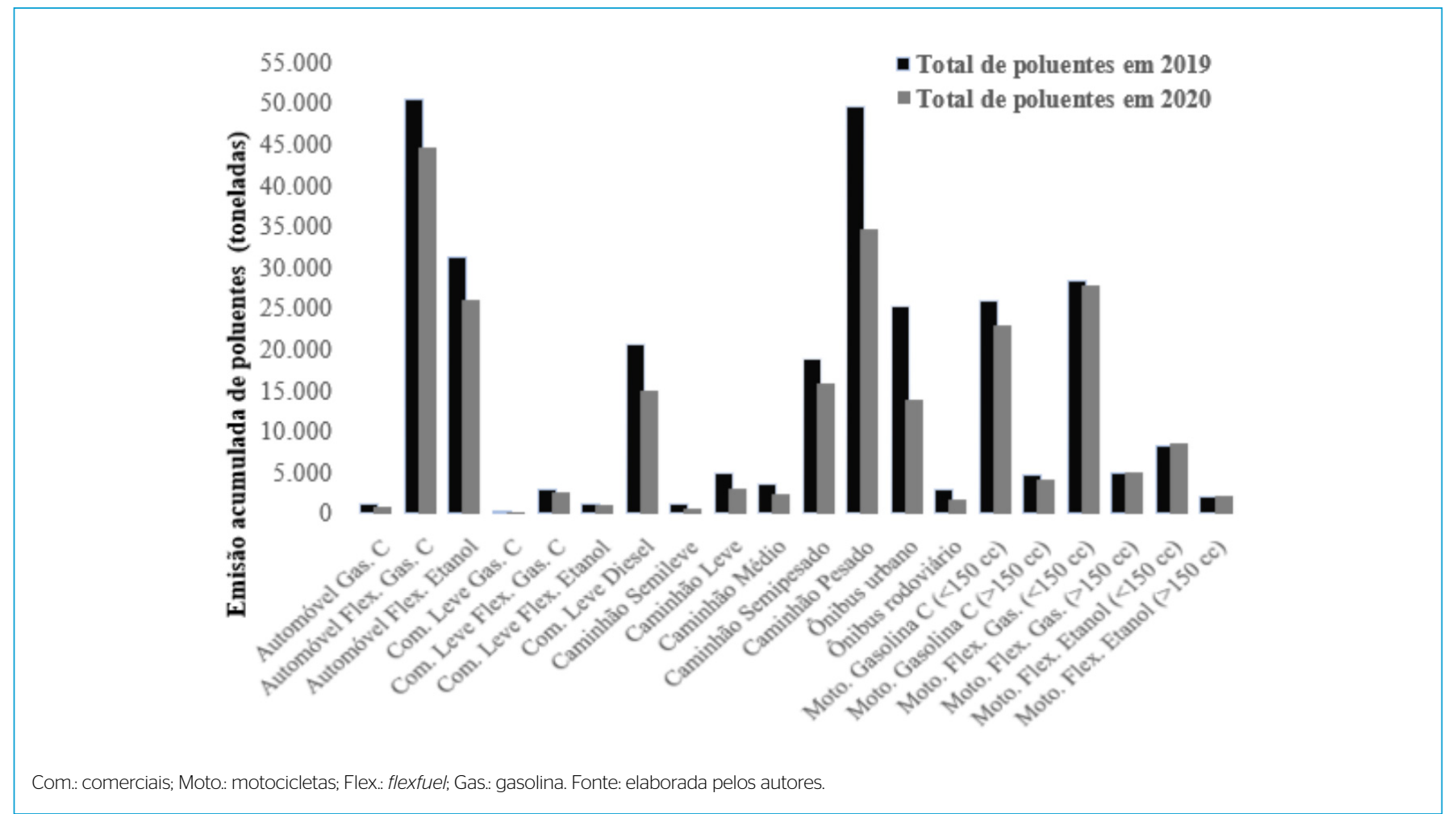

Figura 2 - Comparação entre a emissão acumulada dos poluentes, desagregados por tipo de veículo e combustível, nos cinco primeiros meses de 2020 em relação ao mesmo período de 2019 
Por fim, para as motocicletas, todas apresentaram redução nas emissões, exceto as flexfuel que utilizam o etanol como combustível preferencial, com aumento de $2,1 \%$, corroborando o que já foi mencionando.

\section{CONCLUSÕES}

No presente trabalho foram apresentados dados que mostraram a redução total de $14 \%$ nas emissões dos gases de efeito estufa, com diminuição observada para todos os veículos exceto os caminhões semipesados. Estes tiveram incremento nas emissões de GEE de 12,8\%, provavelmente pelo aumento na intensidade de uso em razão do acréscimo no transporte de encomendas de produtos domésticos, cuja carga é típica desse tipo de veículo.

Em relação aos demais poluentes, houve diminuição de 12,5\% do CO, 29,6 de NOx, 24,1\% de MP, 21,5 de RCHO e 16,3\% de NMHC. No entanto, se considerados os poluentes acumulados, a redução foi de 19,4\%, sendo os ônibus os que sofreram maior decréscimo, provavelmente pela diminuição da intensidade de uso provocada pela queda nas viagens nacionais e pela suspensão das internacionais a partir de março de 2020. Por fim, de todos os veículos analisados, os únicos que tiveram aumento nas emissões dos poluentes acumulados em relação a 2019 foram as motocicletas com tecnologia flexfuel, que usam o etanol hidratado como combustível preferencial. Esse fato foi relacionado ao aumento no volume dos pedidos de entrega de alimentos e demais produtos em domicílio, além da diminuição do preço do álcool em relação à gasolina nos meses de abril e maio de 2020.

Com isso, pôde-se concluir que a pandemia da COVID-19, por meio das medidas de restrição e isolamento social adotadas no Brasil em 2020, impactou positivamente a qualidade do ar no país em virtude da redução das emissões de poluentes advindos dos escapamentos dos veículos automotores licenciados nos primeiros meses do ano, quando comparadas às do mesmo período de 2019.

\section{CONTRIBUIÇÕES DOS AUTORES}

Lobato, M. F.: Conceituação, investigação, Curadoria dos dados, Metodologia, Administração do projeto. Rodrigues, B. M. M.: Conceituação, Metodologia. Santos, A. G. dos: Conceituação, Metodologia, Visualização.

\section{REFERÊNCIAS}

ABRACICLO. Vendas varejo 2019 e 2020. São Paulo: ABRACICLO, 2020. Disponível em: https://www.abraciclo.com.br/site/vendas-varejoemplacamentos/ . Acesso em: 2 jun. 2020.

AGÊNCIA NACIONAL DO PETRÓLEO, GÁS NATURAL E BIOCOMBUSTÍVEIS (ANP). Dados Estatísticos. Anos 2019 e 2020. Brasil: ANP. Disponível em: http://www.anp.gov.br/dados-estatisticos. Acesso em: 14 maio 202Oa.

AGÊNCIA NACIONAL DO PETRÓLEO, GÁS NATURAL E BIOCOMBUSTIVIEIS (ANP). Levantamento de preços e de margens de comercialização de combustíveis. Brasil: ANP. Disponível em: http://www.anp.gov.br/precose-defesa-da-concorrencia/precos/levantamento-de-precos. Acesso em: 14 maio $202 \mathrm{Ob}$

ÁLVARES JR., O.M.; LINKE, R.R.A. Metodologia simplificada de cálculo das emissões de gases do efeito estufa de frotas de veículos no Brasil. São Paulo: CETESB, 2001. 182 p.

ASSOCIAÇÃO NACIONAL DOS FABRICANTES DE VEICULOS AUTOMOTORES (ANFAVEA). Estatísticas. Dados relativos a 2019: produção, vendas, exportação - produção, vendas e exportação de auto veículos. São Paulo: ANFAVEA, 2020. Disponível em: http://www.anfavea.com.br/ estatisticas. Acesso em: 2 jun. 2020.

BRASIL. Agência Nacional de Transportes Terrestres. ANTT suspende viagens internacionais de passageiro. Brasil: Agência Nacional de Transportes Terrestres, 2020a. Disponível em: http://www.antt.gov.br/ salalmprensa/noticias/arquivos/2020/03. Acesso em: 12 jul. 2020.

BRASIL. Ministério da Saúde. Covid-19 - Painel Coronavírus. Brasília: Ministério da Saúde, 2020b. Disponível em: https://covid.saude.gov.br/. Acesso em: 4 jul. 2020.
BRASIL. Ministério do Meio Ambiente. 10 Inventário nacional de emissões atmosféricas por veículos automotores rodoviários: relatório final. Brasília: Ministério do Meio Ambiente, 2011. Disponível em: https://www.mma.gov.br/ estruturas /163/_publicacao/163_publicacao27072011055200.pdf. Acesso em: 4 abr. 2020.

BRASIL. Ministério do Meio Ambiente. 20 Inventário nacional de emissões atmosféricas por veículos automotores rodoviários: relatório final. Brasília: Ministério do Meio Ambiente, 2014. Disponivel em: http://www.antt. gov.br/backend/galeria/arquivos/inventario_de_emissoes_por_veiculos_ rodoviarios_2013.pdf. Acesso em: 4 jul. 2020.

BRASIL. Ministério do Meio Ambiente. Resolução CONAMA no 5: Programa Nacional de Controle da Poluição do Ar - PRONAR. Brasília: Ministério do Meio Ambiente, 1989.

COMPANHIA AMBIENTAL DO ESTADO DE SÃO PAULO (CETESB). Relatório de emissões veiculares no estado de São Paulo no ano de 2018. São Paulo: CETESB, 2019.

CRUVINEL, R.R.S.; PINTO, P.V.H.; GRANEMANN, S.R. Mensuração econômica da emissão de $\mathrm{CO}_{2}$ da frota dos transportadores autônomos de cargas brasileiros. Research Directory, Brasília, v. 6, n. 2, p. 234-252, 2012.

DUTHEIL, F.; BAKER, J.S.; NAVEL, V. COVID-19 as a factor influencing air pollution? Environmental Pollution, v. 263, parte A, 114466, 2020. https://doi org/10.1016/j.envpol.2020.114466

E-COMMERCE.BRASIL. Com pandemia, e-commerce cresce 81\% em abril e fatura $R \$ 9,4$ bilhões. E-commerce.brasil, 2020. Disponível em: https:// www.ecommercebrasil.com.br/noticias/e-commerce-cresce-abril-faturacompreconfie-coronavirus/. Acesso em: 13 jul. 2020. 
EMPRESA DE PESQUISA ENERGÉTICA (EPE). Balanço Energético Nacional: séries históricas. Rio de Janeiro: EPE, 2020. Disponível em: https://www. epe.gov.br/pt/publicacoes-dados-abertos/publicacoes/balanco-energeticonacional-ben. Acesso em: 12 maio 2020

FERREIRA NETTO, R.G.F;; CORREAA, J.W.N. Epidemiologia do surto de doença por coronavírus (Covid-19). Desafios, v. 7, n. esp. 3, p. 18-25, 2020. https://doi.org/10.20873/uftsuple2020-8710

INLOCO. Mapa brasileiro da COVID-19: Indice de isolamento social. Inloco. Disponível em: https://mapabrasileirodacovid.inloco.com.br/pt/. Acesso em: 5 jul. 2020.

LOPES, T.F.A.; POLICARPO, N.A.; VASCONCELOS, V.M.R.; OLIVEIRA, M.L.M. Estimativa das emissões veiculares na região metropolitana de Fortaleza, CE, ano-base 2010. Engenharia Sanitária e Ambiental, Rio de Janeiro, v. 23, n. 5, p. 1013-1025, 2018. https://doi.org/10.1590/S141341522018173312

NTC\&Logística. Covid-19: impacto do coronavírus no transporte rodoviário de carga. NTC\&Logística. Disponível em: https:/www.portalntc.org.br/ demanda-por-transporte-rodoviario-de-cargas-no-brasil-melhora-pela-3semana/. Acesso em: 16 jul. 2020.

ORGANIZAÇÃO MUNDIAL DA SAÚDE (OMS). Relatórios de situação da Covid-19. OMS, 2020. Disponível em: https://www.who.int/emergencies/ diseases/novel-coronavirus-2019/situation-reports/. Acesso em: 4 jul. 2020

Oscar Jr., A.C.; Rocha, J.L. Poluição do ar e doenças respiratórias: estudo de correlação das emissões atmosféricas e impacto nas cidades de Duque de Caxias (RJ) e Petrópolis (RJ) entre 2013 e 2017. Geografia, Londrina, v.2 9, n. 2. p. 219, 2020. https://doi.org/10.5433/2447-1747.2020v29n2p219
PAINEL INTERGOVERNAMENTAL SOBRE MUDANÇAS CLIMÁTICAS (IPCC). National Greenhouse Gas Inventories Programme. IPCC guidelines for National Greenhouse Gas Inventories. IPCC, 2006. v. 2, n. 3. Disponível em: https://www.ipcc-nggip.iges.or.jp/public/2006gl/pdf/2_Volume2/V2_3 Ch3_Mobile_Combustion.pdf. Acesso em: 10 maio 2020.

Rosenbloom, D.; Markard, J.A. COVID-19 recovery for climate. Science, v. 368, n. 6490, p. 447, 2020. https://doi.org/10.1126/science.abc4887

Sciomer, S.; Moscucci, F.; Magrì, D.; Badagliacca, R.; Piccirillo, G.; Agostoni, P. SARS-CoV-2 spread in Northern Italy: what about the pollution role? Environmental Monitoring and Assessment, v. 192, n. 6, p. 325, 2020. https:// doi.org/10.1007/s10661-020-08317-y

SERVIÇO NACIONAL DE APRENDIZAGEM INDUSTRIAL (SENAI) Cartilha inventário de emissões de gases de efeito estufa. Rio de Janeiro: Departamento Regional do Estado do Rio de Janeiro, 2017.

SHARMA, A.K.; BALYAN, P. Air pollution and COVID-19: Is the connect worth its weight? Indian Journal of Public Health, n. 64, p. S132-S134, 2020. https:// doi.org/10.4103/ijph.ijph_466_20

SINGH, R.; SHARMA, C.; AGRAWAL, M. Emission inventory of trace gases from road transport in India. Transportation Research Part D, v. 52, p. 64-72, 2017. https://doi.org/10.1016/j.trd.2017.02.011

United States Environmental Protection Agency (USEPA). Greenhouse Gas Emissions. Washington, D.C.: USEPA. Disponível em: epa.gov/ghgemissions/ understanding-global-warming-potentials. Acesso em: 7 jul. 2020.

WLM/SCANIA. Conheça o mercado de caminhões semi pesados e escolha o veículo ideal. Scania, 2019. Disponível em: https://blogwlmscania.itaipumg. com.br/conheca-o-mercado-dos-caminhoes-semipesados-e-escolha-oveiculo-ideal. Acesso em: 22 ago. 2021. 